\title{
QUALIDADE E VIDA ÚTIL DE MAMÃO 'FORMOSA' MINIMAMENTE PROCESSADO SUBMETIDO A DIFERENTES TRATAMENTOS
}

\author{
SILVA, Joana Diniz Rosa da ${ }^{1}$ \\ BRUNINI, Maria Amália ${ }^{2}$
}

Recebido em: $2008-10-26$

Aprovado em: 2009-01-18

ISSUE DOI: $10.3738 / 1982.2278 .151$

\begin{abstract}
RESUMO: O objetivo deste trabalho foi avaliar a qualidade e vida útil de mamão 'Formosa' minimamente processado e tratados com água bi-destilada, solução de hipoclorito de sódio a $2 \%$, solução de cloreto de cálcio a $1 \%$, solução de ácido ascórbico a $1 \%$ e com solução de ácido cítrico a $1 \%$. Após o tratamento os produtos foram acondicionados em bandejas de polietileno tereftalato, revestidas externamente com filme plástico de PVC, esticável e autoaderente de $0,012 \mathrm{~mm}$ de espessura e armazenados à temperatura de $5 \pm 1^{\circ} \mathrm{C} \operatorname{com} 85$ a $90 \%$ U.R e à de $9 \pm 1^{\circ} \mathrm{C}$ com 85 a $90 \%$ U.R. Os produtos foram avaliados, diariamente, quanto à perda de massa fresca, taxa respiratória, acidez total titulável, sólidos solúveis totais, carboidrato solúvel, vitamina $\mathrm{C}$, textura e aparência. Através dos resultados obtidos pode-se concluir que o mamão minimamente processado e tratado com água bi-destilada e solução de hipoclorito de sódio a $2 \%$ tiveram vida útil de seis dias, independente da temperatura de armazenamento; a temperatura de $9 \pm 1^{\circ} \mathrm{C}$ foi a que proporcionou as maiores perdas de massa fresca; a taxa respiratória variou durante todo o período de armazenamento; após o corte, os valores de acidez total titulável, sólidos solúveis totais e carboidratos solúveis sofreram interferência dos tratamentos e oscilaram durante todo o período de armazenamento; nos produtos armazenados à $5 \pm 1^{\circ} \mathrm{C}$ o uso de solução de hipoclorito de sódio e nos armazenados à $9 \pm 1^{\circ} \mathrm{C}$ o uso de água destilada sobressaiu na retenção dos teores de vitamina $\mathrm{C}$ ao final do período de armazenamento; a textura dos produtos minimamente processados, independente do tratamento e da temperatura de armazenamento, diminuiu; a aparência externa do mamão minimamente processado e tratado com água bi-destilada e solução de hipoclorito de sódio a $2 \%$ apresentaram notas dentro do limite de aceitabilidade ao final do período de armazenamento, independente da temperatura de armazenamento.
\end{abstract}

Palavras-chave: Mamão. Produtos minimamente processados. Vida útil. Qualidade. Armazenamento. Temperatura.

\section{QUALITY AND SHELF LIFE OF 'FORMOSA' PAPAYA MINIMALLY PROCESSED SUBMETTED AT DIFFERENTS TREATMENTS}

SUMMARY: The objective of this work was to evaluate the quality and shelf life of Formosa" papaya minimally processed and treated with bi-destilled water, sodium hypochlorite at $2 \%$ solution, calcium chloride at $1 \%$ solution, ascorbic acid at $1 \%$ solution, citric acid at $1 \%$ solution, packged into polyethylene terephthalate trays covered with PVC plastic film with $0,012 \mathrm{~mm}$ of thickness and stored at

\footnotetext{
1 Engenheira Agrônoma, Pós-Graduanda do curso de Especialização de Agronegócio e Desenvolvimento Sustentável da Faculdade "Dr Francisco Maeda”, Ituverava/SP. Av. Dr. Paulo Borges de Oliveira, 1305. Jardim Tropical, Ituverava-SP, CEP: 1500-000, e-mail: jodiniz2@yahoo.com.br

Professora Adjunto Aposentada da Faculdade de Ciências Agrárias e Veterinárias 'Campus' de Jaboticabal/UNESP e Professora Doutora da Faculdade "Dr Francisco Maeda" /Fundação Educacional de Ituverava. Rodovia Jerônimo Nunes Macedo, km 1, CEP: 14500-000. Ituverava-SP. E-mail: amaliabrunini@ netsite.com.br; brunini@feituverava.com.br
} 
$5 \pm 1^{\circ} \mathrm{C}$ with 85 to $90 \%$ R.U and at $9 \pm 1^{\circ} \mathrm{C}$, with 85 to $90 \%$ R.U. The papaya minimally processed were evaluated to fresh weigh lost, respiratory rate, titrable acidily, total soluble solids, soluble carbohydrates, vitamin $\mathrm{C}$, and texture appearance. The papaya a minimally processed treated with bi-distilled water and sodium hipochlorite at $2 \%$ solution had shelf life of six days, independent of storage temperature; the respiration rate varied during the the storage time; after cut the tatrable acidity, soluble solid and soluble carbohydrate had interference of the treatments and varied during storage time; in the papaya minimally processed and stored at $5 \pm 1{ }^{\circ} \mathrm{C}$ the use of sodium hypochlorite at $2 \%$ and in the stored at $9 \pm 1{ }^{\circ} \mathrm{C}$ the use of bi-destilled water was the best for retention the vitamin $\mathrm{C}$ values at the ande of storage time; the texture of minimally processed products, independent of temperature storage and treatments decreasing; papaya minimally processed treated with bi-distilled water and hipocholorite $2 \%$ solution had good acceptance, into acceptable limit, independent of the storage temperature.

Keywords: Carica papaya L. Minimally processed products. Shelf life. Quality. Storage. Temperature.

\section{INTRODUÇÃO}

O mamão (Carica papaya L) 'Formosa', pertencente à família Caricaceae, tem boa aceitação entre os consumidores, devido à sua polpa suculenta, aroma e sabor, entretanto para ser consumido precisa ser descascado e fatiado, o que muitas vezes é inconveniente, tornando o seu processamento em produtos mínimos prático para os consumidores, além de agregar valor ao produto.

O processamento de frutas e hortaliças em produtos mínimos compreende operações que eliminam as partes não comestíveis, como cascas, sementes ou caroço, seguidos pelo corte em tamanhos menores, tornando-os prontos para consumo imediato com características semelhantes a do produto fresco (BRUNINI et al., 2004; DURIGAN, 2000; CHITARRA, 1998; CANTWELL, 1995; BOLIN; HUXSOL, 1989), como também apresentam exigências específicas de preparo, de cadeia de frio, de sistema de embalagens, de cadeia de transporte e comercialização para que sejam garantidas as suas qualidades organolépticas, nutricionais e microbiológicas. Entretanto, o que se tem observado é que as informações disponíveis na literatura são na maioria de outros países, com maior tradição nessa atividade, não podendo ser introduzidas no Brasil sem adaptações, o que muitas vezes entravam o desenvolvimento do setor.

Segundo Tatsumi et al. (1991), Rosen e Kader (1989) os produtos minimamente processados são muito mais perecíveis do que os íntegros, devido ao severo estresse físico ocasionado, principalmente, pela operação de corte, que aumenta o seu metabolismo. Esse estresse ocasiona o escurecimento dos tecidos, aumenta a taxa respiratória e reduz a qualidade e vida útil dos productos (BRUNINI et al., 2004; VITTI et al., 2003; BURNS, 1995; BRECHT, 1995; ALVES, 2000)

O processamento mínimo de frutas e hortaliças, também, aumenta a perecibilidade, exigindo técnicas de conservação, como sanitização, preparo e manuseio 
adequados (LIMA, 2000), o que exige técnicas que visam à preservação do produto com a mesma qualidade do fruto íntegro.

Dentre os vários métodos que podem ser utilizados na manutenção da qualidade de produtos minimamente processados, pode-se citar a higienização, a refrigeração (BOLIN; HUXSOLL, 1991), o uso de atmosfera modificada ou controlada (ROSEN; KADER, 1989) e tratamentos químicos ou alternativos usados com a finalidade principal de controlar a deterioração, inibirem o escurecimento enzimático e reter a firmeza (BRETCH, 1995). Entre os produtos químicos pode-se citar o uso de ácido cítrico (redução da produção de $\mathrm{CO}_{2}$ e escurecimento), cloreto de cálcio (manutenção da firmeza), ácido ascórbico (inibição do desenvolvimento de escurecimento) e a associação entre produtos firmadores da integridade celular e antioxidantes.

Pelo exposto, o presente trabalho tem como objetivo avaliar a qualidade e a vida útil de mamão 'Formosa' minimamente processado, submetido a diferentes tratamentos, acondicionados em bandejas de polietileno tereftalato, revestidas externamente com filme plástico de PVC, esticável e autoaderente de 0,012mm de espessura, revestidas externamente com filme plástico de PVC, esticável e auto-adquirente e armazenados à temperatura de $5 \pm 1^{\circ} \mathrm{C}$ e à $9 \pm 1^{\circ} \mathrm{C}, \operatorname{com} 85$ a $90 \%$.

\section{MATERIAL E MÉTODOS}

A matéria prima utilizada foi mamão do cultivar 'Formosa', proveniente do CEAGESP-Entreposto de Ribeirão Preto-SP, no estádio de maturação 'maduro', com peso médio de $1,4 \mathrm{~kg}$. Os frutos foram transportados, em caixas plásticas, para o Laboratório de Pré-processamento de Frutas e Hortaliças da Faculdade 'Dr Francisco Maeda' da Fundação Educacional de Ituverava - SP - FAFRAM/FE, onde foram lavados com água corrente e detergente para retirada de impurezas e posteriormente submetidos a processo de higienização através de lavagem com solução de hipoclorito de sódio a $200 \mathrm{mg}$ por litro por 5 minutos e secos ao ambiente em bancadas, também higienizadas com solução de hipoclorito de sódio a 200 mg por litro. Após secos, os frutos foram deixados por, aproximadamente, 12 horas em câmara fria à temperatura de $11 \pm 1{ }^{\circ} \mathrm{C}$, antes de serem submetidos ao processamento.

Os mamões foram descascados e cortados ao meio com auxílio de faca de aço inoxidável, as sementes retiradas com auxílio de colher de aço inoxidável e, após cortados na forma de cubos de, aproximadamente, $2,5 \mathrm{~cm}$ de aresta. A seguir, os produtos minimamente processados foram divididos em cinco lotes, que foram 
submetidos, aos seguintes tratamentos: os produtos do primeiro lote foram imersos em água bi-destilada, durante 3 minutos; os do segundo sanitizados por imersão, durante 3 minutos, em solução de hipoclorito de sódio a 20mg por litro; os do terceiro tratados por imersão, durante 3 minutos, com solução de ácido ascórbico a 1\%; os do quarto lote tratados por imersão, durante 3 minutos, com solução de cloreto de cálcio a 1\% e os do quinto tratados por imersão, durante 3 minutos, em solução de ácido cítrico a 1\%. Após serem submetidos aos tratamentos, os produtos foram escorridos, por cinco minutos, em escorredor doméstico higienizado com solução de hipoclorito de sódio a $200 \mathrm{mg}$ por litro, e posteriormente acondicionados em bandejas de polietileno tereftalato (com

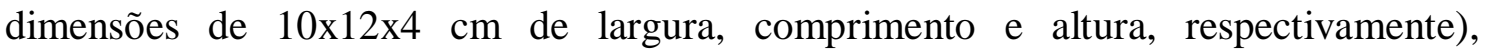
revestidas externamente com filme plástico de cloreto de polivinila, esticável e autoaderente de $12 \mu \mathrm{m}$ de espessura. Cada bandeja, dentro de cada tratamento correspondeu a uma unidade experimental.

As unidades experimentais de cada tratamento foram armazenadas à $5 \pm 1^{\circ} \mathrm{C} \mathrm{com}$ $85-90 \%$ UR e à $9 \pm 1{ }^{\circ} \mathrm{C}, \operatorname{com} 85$ a $90 \%$ até a perda de aspecto de 'frescor'.

A avaliação dos produtos minimamente processados de mamão foi realizada no início do experimento e, diariamente, quanto à perda de massa fresca, que foi determinada em balança Gehaka, com capacidade 2000g e precisão 0,01, e calculada pela diferença entre a massa fresca obtida no dia da amostragem e a massa inicial das unidades experimentais e transformada em porcentagem; taxa respiratória que foi determinada através de produção de gás carbônico pelo produto minimamente processado segundo Botelho (1996), que baseia-se na capacidade de soluções básicas reagirem com o gás carbônico, retendo-o em solução na forma de íon carbonato, e os resultados foram expressos em $\mathrm{mg}$ de $\mathrm{CO}_{2} \cdot \mathrm{Kg}^{-1} \cdot \mathrm{h}^{-1}$; acidez total titulável que foi determinada por método titulométrico utilizando solução padronizada de hidróxido de sódio $0,05 \mathrm{~N}$, e os resultados expressos em g de ácido cítrico por $100 \mathrm{~g}$ de amostra (AOAC, 1997); sólidos solúveis totais que foram determinados, diretamente no produto triturado, por refratometria, através do refratômetro digital Atago Palette PR-101 e expresso em ${ }^{\circ}$ Brix (AOAC, 1997); carboidrato solúvel total determinado pelo método do fenol-sulfúrico, segundo Dubois et al. (1956) e os resultados expressos em g de glicose por 100g de polpa; vitamina $\mathrm{C}$ que foi determinado por método titulométrico utilizando reativo de Tillmans (solução de 2,6 dicloroindofenol de sódio), e os resultados expressos em mg de ácido ascórbico por 100g de amostra (INSTITUTO ADOLFO LUTZ, 1985) e a aparência que foi determinada visualmente, utilizando uma 
escala de notas de 1 a 4, onde: 4 = ótima; 3 = boa; 2 = razoável e $1=$ péssima.

Os produtos minimamente processados foram avaliados segundo delineamento composto: tratamentos (5) e temperatura de armazenamento (2), segundo Banzatto e Kronka (1995) e para interpretação dos resultados utilizaram-se as seguintes siglas:

- $\mathrm{MA}=$ Mamão minimamente processado, tratado com água bi-destilada por 3 minutos, e acondicionado em bandejas de polietileno tereftalato revestidas externamente com filme plástico de PVC, esticável e autoaderente de 0,012mm;

- $\mathrm{MB}=$ Mamão minimamente processado, tratado com solução de hipoclorito de sódio a $2 \%$ por 3 minutos e acondicionado em bandejas de polietileno tereftalato, revestidas externamente com filme plástico de PVC, esticável e autoaderente de 0,012mm;

- $\quad \mathrm{MC}=$ Mamão minimamente processado, tratado com solução de ácido ascórbico a $1 \%$ por 3 minutos, e acondicionado em bandejas de polietileno tereftalato, revestidas externamente com filme plástico de PVC, esticável e autoaderente de $0,012 \mathrm{~mm}$;

- $\mathrm{MD}=$ Mamão minimamente processado, tratado com solução de cloreto de cálcio a $1 \%$ por 3 minutos e acondicionado em bandejas de polietileno tereftalato, revestidas externamente com filme plástico de PVC, esticável e autoaderente de $0,012 \mathrm{~mm}$;

- $\mathrm{ME}=$ Mamão minimamente processado, tratado com solução de ácido cítrico a $1 \%$ por 3 minutos e acondicionado em bandejas de polietileno tereftalato, revestidas externamente com filme plástico de PVC, esticável e autoaderente de $0,012 \mathrm{~mm}$;

\section{RESULTADOS E DISCUSSÃO}

O processamento mínimo de frutas e hortaliças é um empreendimento voltado para a verticalização agrícola, visando agregação de valor e conseqüentemente melhor preço para a comercialização. Os valores de perda de massa fresca do mamão minimamente processado (Tabela 1) apresentam ligeira diferença estatística durante o armazenamento. Os mamões minimamente processados e tratados com solução de ácido cítrico a $1 \%$ foram os que apresentaram as menores perdas ao final do período de armazenamento em ambas as temperaturas, fato este que pode ser atribuído ao menor tempo de armazenamento (3 dias), pois segundo Kader (1992), a perda de água pelos 
tecidos acarreta perdas quantitativas, influência a aparência, as qualidades texturais e nutricionais de um produto. Entretanto, a vida útil dos produtos minimamente processados tratados com acido cítrico a $1 \%$ foi de três dias em ambas as temperaturas de armazenamento.

Através dos dados da Tabela 1, pode-se verificar que a temperatura de $9 \pm 1^{\circ} \mathrm{C}$ foi a que proporcionou as menores perdas de massa fresca, em relação aos produtos minimamente processados submetidos ao mesmo tratamento e armazenado à $5 \pm 1^{\circ} \mathrm{C}$, mostrando sua eficiência neste parâmetro.

TABELA 1: Variação da perda de massa fresca, expressa em porcentagem, em mamão 'Formosa' minimamente processado, submetido a diferentes tratamentos durante armazenamento a $5 \pm 1^{\circ} \mathrm{C}$ e $9 \pm 1^{\circ} \mathrm{C}$. (Média de 8 repetições).

\begin{tabular}{|c|c|c|c|c|c|c|}
\hline \multirow{2}{*}{ Tratamentos $^{(1)}$} & \multicolumn{6}{|c|}{ Período de armazenamento (dias) } \\
\hline & 1 & 2 & 3 & 4 & 5 & 6 \\
\hline \multicolumn{7}{|c|}{$5 \pm 1^{\circ} \mathrm{C} \operatorname{com} 85-90 \%$ UR } \\
\hline MA & $0,32 b$ & $0,58 b$ & $0,70 b$ & $1,71 \mathrm{a}$ & $1,24 \mathrm{a}$ & $2,77 \mathrm{a}$ \\
\hline $\mathrm{MB}$ & $0,81 \mathrm{a}$ & $1,21 \mathrm{a}$ & $1,49 a$ & $1,94 \mathrm{a}$ & $1,81 b$ & $2,10 b$ \\
\hline $\mathrm{MC}$ & $0,55 \mathrm{ab}$ & $0,59 b$ & $1,37 \mathrm{a}$ & $1,10 \mathrm{a}$ & & \\
\hline MD & $0,76 \mathrm{a}$ & $1,03 \mathrm{a}$ & $1,45 \mathrm{a}$ & & & \\
\hline $\mathrm{ME}$ & $0,38 b$ & $0,59 b$ & $0,85 b$ & & & \\
\hline d.m.s. ${ }^{(2)}$ & 0,3028 & 0,4195 & 0,4819 & 1,0652 & 0,4050 & 0,4615 \\
\hline$s^{(2)}$ & 0,1386 & 0,1920 & 0,2206 & 0,5393 & 0,2341 & 0,2668 \\
\hline $\mathrm{F}^{(2)}$ & $10,02 * *$ & $10,45 * *$ & $10,97 * *$ & $2,57 \mathrm{~ns}$ & $6,75^{*}$ & $12,90 *$ \\
\hline c.v. ${ }^{(2)}$ & 24,40 & 20,86 & 18,80 & 34,10 & 11,56 & 10,95 \\
\hline \multicolumn{7}{|c|}{$9 \pm 1^{\circ} \mathrm{C}$ com $85-90 \%$ UR } \\
\hline MA & $0,36 \mathrm{a}$ & $0,51 \mathrm{a}$ & $0,59 \mathrm{a}$ & $0,70 \mathrm{a}$ & $0,78 \mathrm{a}$ & $0,86 a$ \\
\hline $\mathrm{MB}$ & $0,36 a$ & $0,53 \mathrm{a}$ & $0,63 a$ & $0,37 b$ & $0,42 b$ & $0,82 \mathrm{a}$ \\
\hline $\mathrm{MC}$ & $0,10 b$ & $0,24 b$ & $0,32 b$ & $0,65 \mathrm{a}$ & $0,77 \mathrm{a}$ & \\
\hline MD & $0,33 a$ & $0,49 \mathrm{a}$ & $0,59 a$ & $0,72 \mathrm{a}$ & & \\
\hline $\mathrm{ME}$ & $0,36 \mathrm{a}$ & $0,54 \mathrm{a}$ & $0,65 \mathrm{a}$ & & & \\
\hline d.m.s. ${ }^{(2)}$ & 0,0885 & 0,1596 & 0,1964 & 0,2249 & 0,2099 & 0,2211 \\
\hline$s^{(2)}$ & 0,0405 & 0,0731 & 0,0899 & 0,1071 & 0,1063 & 0,1278 \\
\hline $\mathrm{F}^{(2)}$ & $31,76 * *$ & $11,90 * *$ & $8,83 * *$ & $9,27 * *$ & $14,77 * *$ & $0,13 \mathrm{~ns}$ \\
\hline c.v. ${ }^{(2)}$ & 13,39 & 15,78 & 16,13 & 17,54 & 16,21 & 15,19 \\
\hline
\end{tabular}

Os teores de perda de massa fresca, ao final do período de armazenamento, variaram de $0,85 \%$ a $2,77 \%$ e de $0,65 \%$ a $0,86 \%$, respectivamente, às temperaturas de $5 \pm 1^{\circ} \mathrm{C}$ e $9 \pm 1^{\circ} \mathrm{C}$. Também pode-se observar que os produtos tratados com hipoclorito de sódio foram os que apresentaram a menor perda ao final do armazenamento.

O comportamento aqui observado é coerente com a citação de Chitarra e Chitarra (2005) e Brunini et al. (2004), que os produtos perdem peso após a colheita e 
durante o armazenamento, pois produtos minimamente processados continuam respirando .

A taxa respiratória do mamão minimamente processado, e imediatamente após o corte sofreu incremento de, aproximadamente, sete vezes em relação aos frutos íntegros, e diminuiu no período de vinte e quatro horas. A diferença observada na taxa respiratória dos produtos minimamente processados durante o armazenamento pode ser atribuída ao estresse do produto ocasionado pelo corte (Tabela 2).

TABELA 2: Taxa de respiração, expressa em mg. $\mathrm{CO}_{2} \cdot \mathrm{Kg}^{-1} \cdot \mathrm{h}^{-1}$, em mamão 'Formosa' minimamente processado, submetidos a diferentes tratamentos durante armazenamento a $5 \pm 1^{\circ} \mathrm{C}$ e $9 \pm 1^{\circ} \mathrm{C}$. (Média de 8 repetições).

\begin{tabular}{|c|c|c|c|c|c|c|c|}
\hline \multirow[t]{2}{*}{ Tratamentos } & \multirow{2}{*}{$\begin{array}{l}\text { Fruto } \\
\text { íntegro }\end{array}$} & \multicolumn{6}{|c|}{ Período de armazenamento (dias) } \\
\hline & & inicial & 1 & 2 & 3 & 4 & 5 \\
\hline \multicolumn{8}{|c|}{$5 \pm 1^{\circ} \mathrm{C} \operatorname{com} 85-90 \%$ UR } \\
\hline MA & 198,23 & 1440,60 & $535,04 a$ & $1245,28 \mathrm{c}$ & $473,23 c$ & $99,97 b$ & $1831,74 a$ \\
\hline $\mathrm{MB}$ & & & $81,02 b$ & $1938,42 \mathrm{a}$ & $168,88 d$ & $119,87 \mathrm{~b}$ & $1046,47 b$ \\
\hline $\mathrm{MC}$ & & & $527,79 a$ & $1192,85 c$ & $2023,74 a$ & $916,16 a$ & \\
\hline $\mathrm{MD}$ & & & $477,97 \mathrm{a}$ & $1557,09 b$ & $770,89 b$ & & \\
\hline ME & & & $503,51 \mathrm{a}$ & $315,57 \mathrm{~d}$ & $438,76 \mathrm{c}$ & & \\
\hline d.m.s. ${ }^{(2)}$ & & & 75,4400 & 94,7678 & 141,4258 & 105,6406 & 104,6056 \\
\hline $\mathrm{s}^{(2)}$ & & & 34,5263 & 43,3720 & 64,7258 & 53,4889 & 60,4656 \\
\hline $\mathrm{F}^{(2)}$ & & & $125,81 * *$ & $767,98 * *$ & $508,63 * *$ & $303,07 * *$ & $337,33 * *$ \\
\hline c.v. ${ }^{(2)}$ & & & 8,12 & 3,47 & 8,35 & 14,13 & 4,20 \\
\hline \multicolumn{8}{|c|}{$9 \pm 1^{\circ} \mathrm{C}$ com $85-90 \%$ UR } \\
\hline MA & 198,23 & 1440,60 & $696,22 a$ & $88,18 \mathrm{~d}$ & $679,63 b c$ & $465,11 \mathrm{c}$ & $754,62 \mathrm{a}$ \\
\hline $\mathrm{MB}$ & & & $169,80 \mathrm{~b}$ & $153,06 \mathrm{~d}$ & $595,76 \mathrm{c}$ & $127,07 d$ & $488,88 \mathrm{~b}$ \\
\hline $\mathrm{MC}$ & & & $84,55 b$ & $354,94 \mathrm{c}$ & $184,93 \mathrm{~d}$ & $1222,22 \mathrm{a}$ & \\
\hline MD & & & $630,28 a$ & $3067,25 \mathrm{a}$ & $847,88 \mathrm{a}$ & $933,71 b$ & \\
\hline ME & & & $606,44 a$ & $1639,40 \mathrm{~b}$ & $780,64 \mathrm{ab}$ & & \\
\hline d.m.s. ${ }^{(2)}$ & & & 94,8355 & 106,2070 & 135,5609 & 0,0171 & 87,9261 \\
\hline$s^{(2)}$ & & & 43,4030 & 48,6073 & 62,0416 & 0,0082 & 50,8243 \\
\hline $\mathrm{F}^{(2)}$ & & & $174,31 * *$ & $2805,66^{* *}$ & $70,44 * *$ & & $54,68 * *$ \\
\hline c.v. ${ }^{(2)}$ & & & 9,93 & 4,58 & 10,04 & 0,00 & \\
\hline
\end{tabular}

Os resultados obtidos neste estudo é este coerente com a citação de Vitti et al. (2003) e Chitarra (1998) de que o estresse provocado pelo corte ocasiona perda do compartimento celular, colocando os substratos do metabolismo respiratório em contato com os complexos enzimáticos, aumentando a taxa respiratória, e com a taxa observada por Chevin et al. (1992) em cenouras minimamente processadas, que foi até cinco vezes maior que a inicial, após 30-40 horas. 
A acidez total titulável é em muitos produtos utilizada como critério para classificação dos mesmos quanto ao sabor, sendo, portanto, importante fator de qualidade. A acidez total titulável da polpa do mamão minimante processado, imediatamente, após o corte sofreu incremento de, aproximadamente, 44,76\% em relação à polpa do fruto integro (Tabela 3), e após o período de 48 horas apresentaram diminuição. Pelos dados obtidos referentes à acidez total titulável, pode-se verificar que os teores de acidez titulável foram afetados pelos tratamentos, oscilaram durante o período.

TABELA 3: Acidez total titulável, expressa em g de ácido cítrico por 100g de polpa, em mamão 'Formosa' minimamente processado, submetido a diferentes tratamentos durante armazenamento a $5 \pm 1^{\circ} \mathrm{C}$ e $9 \pm 1^{\circ} \mathrm{C}$. (Média de 8 repetições).

\begin{tabular}{|c|c|c|c|c|c|c|c|}
\hline \multirow[t]{2}{*}{ Tratamentos } & \multirow{2}{*}{$\begin{array}{l}\text { Fruto } \\
\text { íntegro }\end{array}$} & \multicolumn{6}{|c|}{ Período de armazenamento (dias) } \\
\hline & & inicial & 1 & 2 & 3 & 4 & 5 \\
\hline \multicolumn{8}{|c|}{$5 \pm 1^{\circ} \mathrm{C} \operatorname{com} 85-90 \%$ UR } \\
\hline MA & 0,058 & 0,103 & $0,06 \mathrm{c}$ & $0,07 \mathrm{~b}$ & $0,04 \mathrm{c}$ & $0,06 \mathrm{a}$ & $0,09 \mathrm{a}$ \\
\hline MB & & & $0,10 b$ & $0,09 \mathrm{ab}$ & $0,05 b c$ & $0,08 \mathrm{a}$ & $0,06 \mathrm{a}$ \\
\hline $\mathrm{MC}$ & & & $0,090 \mathrm{~b}$ & $0,12 \mathrm{a}$ & $0,05 \mathrm{ab}$ & $0,06 \mathrm{a}$ & \\
\hline MD & & & $0,07 \mathrm{c}$ & $0,06 b$ & $0,06 a b$ & & \\
\hline ME & & & $0,11 \mathrm{a}$ & $0,08 \mathrm{ab}$ & $0,06 \mathrm{a}$ & & \\
\hline d.m.s. ${ }^{(2)}$ & & & 0,0126 & 0,0451 & 0,0088 & 0,0318 & 0,0322 \\
\hline$s^{(2)}$ & & & 0,0058 & 0,0206 & 0,0040 & 0,0161 & 0,0186 \\
\hline $\mathrm{F}^{(2)}$ & & & $53,68 * *$ & $5,81 * *$ & $10,73 * *$ & $2,86 \mathrm{~ns}$ & $5,19 \mathrm{~ns}$ \\
\hline c.v. ${ }^{(2)}$ & & & 6,52 & 24,11 & 7,27 & 22,62 & 25,26 \\
\hline \multicolumn{8}{|c|}{$9 \pm 1^{\circ} \mathrm{C}$ com $85-90 \%$ UR } \\
\hline MA & 0,058 & 0,103 & $0,16 \mathrm{a}$ & $0,07 \mathrm{ab}$ & $0,05 b$ & $0,09 \mathrm{a}$ & $0,08 \mathrm{a}$ \\
\hline MB & & & $0,09 b$ & $0,06 a b$ & $0,05 b$ & $0,10 \mathrm{a}$ & $0,05 b$ \\
\hline $\mathrm{MC}$ & & & $0,09 b$ & $0,10 \mathrm{a}$ & $0,10 \mathrm{a}$ & $0,06 b$ & \\
\hline $\mathrm{MD}$ & & & $0,16 \mathrm{a}$ & $0,07 a b$ & $0,06 \mathrm{~b}$ & $0,06 b$ & \\
\hline $\mathrm{ME}$ & & & $0,14 \mathrm{a}$ & $0,04 b$ & $0,05 b$ & & \\
\hline d.m.s. ${ }^{(2)}$ & & & 0,0227 & 0,0447 & 0,0140 & 0,0196 & 0,0297 \\
\hline$s^{(2)}$ & & & 0,0104 & 0,0205 & 0,0064 & 0,0093 & 0,0172 \\
\hline $\mathrm{F}^{(2)}$ & & & $44,03 * *$ & $3,88^{*}$ & $44,30 * *$ & $22,25 * *$ & $7,05^{*}$ \\
\hline c.v. ${ }^{(2)}$ & & & 7,76 & 30,44 & 10,01 & 11,82 & 25,98 \\
\hline
\end{tabular}

O comportamento aqui observado é coerente ao observado por Benedetti et al. (2000) em pimentões verdes cortados em rodelas e acondicionados em bandejas de poliestireno e armazenados a $5^{\circ} \mathrm{C}$ e $10^{\circ} \mathrm{C}$ por 10 dias, que foi decréscimo de 0,08 para 0,06g por $100 \mathrm{~g}$ e ao decréscimo relatado por Carlin et al. (1990) em cenoura ralada armazenada por 10 dias a $10^{\circ} \mathrm{C}$. Entretanto, o comportamento, aqui observado não é 
coerente com o verificado por Lamikanra et al. (2000) em melão 'Cantaloupe' minimamente processado e armazenado a $4^{\circ} \mathrm{C}$ por 14 dias, que foi aumento nos valores de acidez.

O teor de sólido solúvel total é constituído por açúcares, ácidos orgânicos e outros componentes, entretanto a fração ácida e dos outros componentes é tão pequena comparado à de açúcares que, na prática, consideram-se como sólidos solúveis totais como açúcares. Os teores de sólidos solúveis totais (Tabela 4) variaram em função dos tratamentos, e oscilaram durante todo o período de armazenamento.

TABELA 4: Teores de sólidos solúveis totais, expresso em ${ }^{\circ}$ Brix, em mamão 'Formosa' minimamente processado, submetido a diferentes tratamentos durante armazenamento $5 \pm 1^{\circ} \mathrm{C}$ e $9 \pm 1^{\circ} \mathrm{C}$.(Média de 8 repetições).

\begin{tabular}{|c|c|c|c|c|c|c|c|}
\hline \multirow[t]{2}{*}{ Tratamentos } & \multirow{2}{*}{$\begin{array}{l}\text { Fruto } \\
\text { íntegro }\end{array}$} & \multicolumn{6}{|c|}{ Período de armazenamento (dias) } \\
\hline & & inicial & 1 & 2 & 3 & 4 & 5 \\
\hline \multicolumn{8}{|c|}{$5 \pm 1^{\circ} \mathrm{C} \operatorname{com} 85-90 \%$ UR } \\
\hline MA & 9,78 & 12,8 & $12,75 b$ & $13,00 \mathrm{a}$ & $11,30 \mathrm{~d}$ & $12,52 \mathrm{a}$ & $13,37 \mathrm{a}$ \\
\hline MB & & & $12,70 \mathrm{bc}$ & $13,00 \mathrm{a}$ & $12,35 b$ & $11,85 \mathrm{c}$ & $11,95 b$ \\
\hline $\mathrm{MC}$ & & & $12,02 d$ & $13,02 \mathrm{a}$ & $12,15 \mathrm{c}$ & $12,05 b$ & \\
\hline MD & & & $12,52 \mathrm{c}$ & $12,85 \mathrm{a}$ & $13,62 \mathrm{a}$ & & \\
\hline ME & & & $13,27 \mathrm{a}$ & $12,85 \mathrm{a}$ & $12,05 \mathrm{c}$ & & \\
\hline d.m.s. ${ }^{(2)}$ & & & 0,1892 & 0,1850 & 0,1571 & 0,1435 & 0,0934 \\
\hline$s^{(2)}$ & & & 0,0866 & 0,0847 & 0,0719 & 0,0726 & 0,0540 \\
\hline$F^{(2)}$ & & & $107,90 * *$ & $4,26^{*}$ & $550,26 * *$ & $91,11 * *$ & $1392,43 * *$ \\
\hline c.v. ${ }^{(2)}$ & & & 0,68 & 0,65 & 0,58 & 0,60 & 0,43 \\
\hline \multicolumn{8}{|c|}{$9 \pm 1^{\circ} \mathrm{C} \operatorname{com} 85-90 \%$ UR } \\
\hline MA & 9,78 & 12,8 & $12,95 b$ & $12,85 \mathrm{~b}$ & $14,30 \mathrm{a}$ & $12,07 \mathrm{c}$ & $11,00 \mathrm{~b}$ \\
\hline MB & & & $10,55 \mathrm{c}$ & $11,65 d$ & $12,30 \mathrm{~d}$ & $10,27 d$ & $12,27 \mathrm{a}$ \\
\hline $\mathrm{MC}$ & & & $10,27 d$ & $10,95 \mathrm{e}$ & $11,27 \mathrm{e}$ & $13,52 \mathrm{a}$ & \\
\hline MD & & & $13,67 \mathrm{a}$ & $14,37 \mathrm{a}$ & $13,82 b$ & $12,95 b$ & \\
\hline ME & & & $12,92 b$ & $12,45 \mathrm{c}$ & $13,02 \mathrm{c}$ & & \\
\hline d.m.s. ${ }^{(2)}$ & & & 0,2274 & 0,1230 & 0,2274 & 0,1632 & 0,1171 \\
\hline$s^{(2)}$ & & & 0,1041 & 0,0563 & 0,1041 & 0,0777 & 0,0677 \\
\hline$F^{(2)}$ & & & $887,42^{* *}$ & $2133,32 * *$ & $537,39 * *$ & $1332,79 * *$ & $709,36 * *$ \\
\hline c.v. ${ }^{(2)}$ & & & 0,86 & 0,45 & 0,80 & 0,64 & 0,58 \\
\hline
\end{tabular}

Os produtos tratados com água bi-destilada e solução de cloreto de cálcio a 1\%, foram os que apresentaram os maiores valores ao final do tempo de armazenamento a $5 \pm 1^{\circ} \mathrm{C}$, respectivamente, $13,37^{\circ} \mathrm{Brix}$ e $13,62^{\circ} \mathrm{Brix}$, enquanto que a $9 \pm 1^{\circ} \mathrm{C}$, foram os produtos tratados com solução de ácido ascórbico a $1 \%$ e solução de ácido cítrico a $1 \%$ que apresentaram os maiores valores, $13,52^{\circ}$ Brix e $13,02^{\circ}$ Brix, respectivamente. No 
geral pode-se observar pelos dados da Tabela 4, que os teores de sólidos solúveis totais nos produtos minimamente processados são semelhantes à da polpa íntegra.

A vitamina $\mathrm{C}$ é uma vitamina termolábil, sensível à luz, oxigênio, estável em meio ácido e instável em meio alcalino, oxigênio e calor (OLIVEIRA; MARCHINI, 1998; CHEFT e CHEFT, 1989), além de ser um fator importante na nutrição humana devido ajudar no aproveitamento do ferro pelo organismo humano (HUNT et al., 1990; CAMBRAIA et al., 1971; OLIVEIRA; MARCHINI, 1998). Segundo Chitarra (1999) o corte dos tecidos durante o preparo de produtos minimamente processados ocasiona rápida perda de vitamina $\mathrm{C}$.

No presente trabalho, as perdas de vitamina $\mathrm{C}$ foram influenciadas pelos tratamentos e pelo tempo de armazenamento em relação ao valor da polpa do fruto íntegro Nos produtos minimamente processados e armazenados a $5 \pm 1^{\circ} \mathrm{C}$, ocorreu aumento considerável do teor de vitamina $\mathrm{C}$ em relação ao valor imediatamente após o corte (Tabela 5), o que pode ser atribuído à perda de água pelos produtos, que provavelmente aumentou os teores de sólidos totais. O comportamento aqui observado não está de acordo com Sgarbieri (1987), que cita que quanto mais baixa a temperatura, menor a intensidade respiratória dos vegetais e perda de umidade preservando os nutrientes termolábeis.

Através dos dados obtidos neste estudo pode-se verificar que as temperaturas de armazenamento não foram eficazes na manutenção do teor de vitamina $\mathrm{C}$, pois ocorreram oscilações do valor durante o armazenamento em relação ao valor obtido logo após o corte.

Os teores de carboidratos solúveis (Tabela 6) foram afetados pelos tratamentos a que os produtos foram submetidos, e oscilaram durante todo o período de armazenamento. Ao final do período de armazenamento, os produtos minimamente processados apresentaram diminuição nos teores de carboidratos solúveis em relação ao valor da polpa do fruto integro, da ordem de 80 a 90\%, redução esta que pode estar relacionada à quantidade de suco extravasado dos produtos, pois segundo Watada et al., (1990), a ação física do processamento na respiração dos tecidos, provoca rapidamente o uso dos substratos de reserva. 
TABELA 5: Teores de vitamina C, expresso em $\mathrm{mg}$ de ácido ascórbico por $100 \mathrm{~g}$ de polpa, em mamão 'Formosa' minimamente processado, submetido a diferentes tratamentos durante armazenamento a $5 \pm 1^{\circ} \mathrm{C}$ e $9 \pm 1^{\circ} \mathrm{C}$. (Média de 8 repetições).

\begin{tabular}{|c|c|c|c|c|c|c|c|}
\hline \multirow[t]{2}{*}{ Tratamentos } & \multirow{2}{*}{$\begin{array}{c}\text { Fruto } \\
\text { íntegro }\end{array}$} & \multicolumn{6}{|c|}{ Período de armazenamento (dias) } \\
\hline & & inicial & 1 & 2 & 3 & 4 & 5 \\
\hline \multicolumn{8}{|c|}{$5 \pm 1^{\circ} \mathrm{C} \operatorname{com} 85-90 \%$ UR } \\
\hline MA & 27,05 & 57,17 & $41,50 \mathrm{~d}$ & $37,43 \mathrm{c}$ & $37,29 \mathrm{e}$ & $45,32 \mathrm{c}$ & $61,35 b$ \\
\hline MB & & & $30,96 \mathrm{e}$ & $30,08 \mathrm{e}$ & $62,97 \mathrm{~b}$ & $65,25 \mathrm{a}$ & $85,84 \mathrm{a}$ \\
\hline $\mathrm{MC}$ & & & $57,13 \mathrm{~b}$ & $58,04 \mathrm{a}$ & $65,12 \mathrm{a}$ & $50,86 \mathrm{~b}$ & \\
\hline MD & & & $65,39 \mathrm{a}$ & $34,30 \mathrm{~d}$ & $60,94 \mathrm{c}$ & & \\
\hline ME & & & $42,72 \mathrm{c}$ & $48,82 \mathrm{~b}$ & $50,83 \mathrm{~d}$ & & \\
\hline d.m.s. ${ }^{(2)}$ & & & 0,5088 & 0,5614 & 0,5501 & 0,4537 & 0,4296 \\
\hline $\mathrm{s}^{(2)}$ & & & 0,2478 & 0,2569 & 0,2517 & 0,2297 & 0,2483 \\
\hline $\mathrm{F}^{(2)}$ & & & $6872,55 * *$ & $3979,64 * *$ & $4191,65 * *$ & $4010,40 * *$ & $9725,84 * *$ \\
\hline c.v. ${ }^{(2)}$ & & & 0,24 & 0,31 & 0,22 & 0,21 & 0,17 \\
\hline \multicolumn{8}{|c|}{$9 \pm 1^{\circ} \mathrm{C} \operatorname{com} 85-90 \%$ UR } \\
\hline MA & 27,05 & 57,17 & $77,63 b$ & $54,14 \mathrm{~b}$ & $44,36 \mathrm{~d}$ & $46,97 b$ & $51,80 \mathrm{a}$ \\
\hline MB & & & $50,78 \mathrm{~d}$ & $44,54 \mathrm{c}$ & $47,42 b$ & $59,23 \mathrm{a}$ & $50,65 b$ \\
\hline $\mathrm{MC}$ & & & $79,12 \mathrm{a}$ & $56,85 b$ & $60,87 \mathrm{a}$ & $46,91 b$ & \\
\hline MD & & & $67,37 \mathrm{c}$ & $63,08 \mathrm{a}$ & $46,69 \mathrm{c}$ & $41,22 \mathrm{c}$ & \\
\hline ME & & & $51,11 \mathrm{~d}$ & $38,19 \mathrm{c}$ & $41,17 \mathrm{e}$ & & \\
\hline d.m.s. ${ }^{(2)}$ & & & 1,2209 & 6,7623 & 0,6847 & 0,5426 & 0,4308 \\
\hline$s^{(2)}$ & & & 0,5588 & 3,094 & 0,3134 & 0,2584 & 0,249 \\
\hline $\mathrm{F}^{(2)}$ & & & $1149,72 * *$ & $22,71 * *$ & $1158,31 * *$ & $1723,01 * *$ & $21,42 * *$ \\
\hline c.v. ${ }^{(2)}$ & & & 0,42 & 3,02 & 0,32 & 0,26 & 0,24 \\
\hline
\end{tabular}

A aparência externa é um ponto fundamental a ser avaliado em frutos destinados ao mercado por ser fator de atratividade e exercer influência direta sobre a escolha do consumidor (JERONIMO; KANESIRO, 2000), e neste estudo, a aparência do mamão minimamente processado (dados não mostrados) foi considerada boa, pois não ocorrem desenvolvimento de escurecimento, e a inibição do desenvolvimento de bolores e fungos, observados pode ser atribuído às condições higiênico-sanitária utilizada no manuseio e preparo dos produtos que foram de acordo com as recomendações do Regulamento Técnico sobre condições higiênico-sanitárias e Boas Práticas de Fabricação (BRASIL, 1997; SILVA JÚNIOR, 2001).

O comportamento aqui observado, para aparência é coerente com O'CannorShaw et al. (1994), que também não observaram mudanças significativas na aparência de mamões 'honeydew' minimamente processados e armazenados a $4^{\circ} \mathrm{C}$ por 14 dias. 
TABELA 6: Carboidrato Solúvel, expresso em g de glicose por 100 gramas de polpa, em mamão 'Formosa' minimamente processado submetidos a tratamentos químicos durante armazenamento em diferentes temperaturas. (Média de 8 repetições).

\begin{tabular}{|c|c|c|c|c|c|c|c|}
\hline \multirow[t]{2}{*}{ Tratamentos $^{(1)}$} & \multirow{2}{*}{$\begin{array}{c}\text { Fruto } \\
\text { Integro }\end{array}$} & \multicolumn{6}{|c|}{ Tempo de armazenamento (dias) } \\
\hline & & Inicial & 1 & 2 & 3 & 4 & 5 \\
\hline \multicolumn{8}{|c|}{, com $85 \%$ a $90 \%$ UR } \\
\hline MA & 12,65 & 25,68 & $26,08 \mathrm{~d}$ & $14,38 \mathrm{~d}$ & $9,02 \mathrm{c}$ & & \\
\hline MB & & & $24,97 \mathrm{e}$ & $13,41 \mathrm{e}$ & $7,66 \mathrm{~d}$ & $6,88 \mathrm{c}$ & $3,16 b$ \\
\hline $\mathrm{MC}$ & & & $29,57 \mathrm{c}$ & $24,73 a$ & $9,97 \mathrm{~b}$ & $9,87 \mathrm{~b}$ & \\
\hline MD & & & $30,43 b$ & $20,85 b$ & $14,45 \mathrm{a}$ & $10,12 \mathrm{a}$ & $4,84 \mathrm{a}$ \\
\hline ME & & & $34,75 \mathrm{a}$ & $20,64 \mathrm{c}$ & $7,43 \mathrm{e}$ & $6,10 \mathrm{~d}$ & \\
\hline $\mathrm{dms}^{(2)}$ & & & 0,1572 & 0,1234 & 0,0922 & 0,1688 & 0,1186 \\
\hline$S^{(2)}$ & & & 0,0585 & 0,0460 & 0,0344 & 0,0645 & 0,0523 \\
\hline $\mathrm{F}^{(2)}$ & & & $13160,99 * *$ & $32428,39 * *$ & $4870,97 * *$ & $3027,67 * *$ & $1561,20 * *$ \\
\hline $\mathrm{cV}^{(2)}$ & & & 0,20 & 0,24 & 0,51 & 0,78 & 1,31 \\
\hline \multicolumn{8}{|c|}{$9 \pm 1^{\circ} \mathrm{C}, \operatorname{com} 85 \%$ a $90 \%$ UR } \\
\hline$\overline{\mathrm{MA}}$ & 12,65 & 25,68 & $32,55 b$ & $14,65 \mathrm{e}$ & $7,38 \mathrm{c}$ & & \\
\hline MB & & & $34,91 \mathrm{a}$ & $30,52 b$ & $11,70 \mathrm{a}$ & $9,58 \mathrm{a}$ & $5,71 b$ \\
\hline $\mathrm{MC}$ & & & $22,60 \mathrm{c}$ & $14,85 \mathrm{~d}$ & $11,24 b$ & $8,61 b$ & 7,39a \\
\hline MD & & & $13,17 \mathrm{e}$ & $16,82 \mathrm{c}$ & $6,30 \mathrm{e}$ & & \\
\hline ME & & & $19,10 \mathrm{~d}$ & $33,29 a$ & $6,86 \mathrm{~d}$ & $6,95 c$ & \\
\hline $\mathrm{dms}^{(2)}$ & & & 0,1451 & 0,1234 & 0,1109 & 0,1738 & 0,0854 \\
\hline$S^{(2)}$ & & & 0,0540 & 0,0460 & 0,0413 & 0,0694 & 0,0376 \\
\hline $\mathrm{F}^{(2)}$ & & & $85865,68 * *$ & $2491064 * *$ & $11573,91 * *$ & $1105,98 * *$ & $3000,29 * *$ \\
\hline $\mathrm{cV}^{(2)}$ & & & 0,22 & 0,21 & 0,47 & 0,83 & 0,57 \\
\hline
\end{tabular}

Ao se comparar o efeito dos diferentes tratamentos químicos na textura do mamão minimamente processado (Tabela 7), pode-se verificar que a partir dos 3 dias a mesma temperatura não foi influenciada. Também pode-se verificar que o processamento do mamão em produtos minimamente processados diminuiu a firmeza da textura dos produtos em cerca de $17,74 \%$, em relação à da polpa do fruto íntegro, provavelmente, devido a que neste tipo de processamento pode ter ocorrido acelerações do metabolismo, levando a um amolecimento da póla, conforme citação de Burns (1195), Brecht (1995) e Alves (2000).

Os produtos minimamente processados armazenados à $5 \pm 1^{\circ} \mathrm{C}$ e tratados com água bi-destilada e solução de hipoclorito de sódio a $2 \%$ tiveram vida útil de seis dias, os tratados com

ácido ascórbico a $1 \%$ tiveram vida útil de quatro dias, enquanto que os tratados com solução de ácido cítrico e cloreto de cálcio tiveram três dias. 
TABELA 7: Textura do fruto, expressa em $\mathrm{Kgf.cm}^{-2}$, em mamão 'Formosa' minimamente processado, submetido a diferentes tratamentos durante armazenamento a $5 \pm 1^{\circ} \mathrm{C}$ e $9 \pm 1^{\circ} \mathrm{C}$. (Média de 8 repetições).

\begin{tabular}{|c|c|c|c|c|c|c|c|}
\hline \multirow{2}{*}{ Tratamentos } & \multirow{2}{*}{$\begin{array}{l}\text { Fruto } \\
\text { íntegro }\end{array}$} & \multicolumn{6}{|c|}{ Período de armazenamento (dias) } \\
\hline & & inicial & 1 & 2 & 3 & 4 & 5 \\
\hline \multicolumn{8}{|c|}{$5 \pm 1^{\circ} \mathrm{C}$ com $85-90 \%$ UR } \\
\hline MA & 97,49 & 24,86 & $16,24 b$ & $40,55 b$ & $18,52 \mathrm{a}$ & $12,09 \mathrm{a}$ & $17,35 \mathrm{a}$ \\
\hline MB & & & $18,34 b$ & $37,43 b c$ & $7,80 \mathrm{bc}$ & $10,14 \mathrm{a}$ & $15,01 \mathrm{a}$ \\
\hline $\mathrm{MC}$ & & & $20,66 a b$ & $27,69 b c$ & $16,96 \mathrm{ab}$ & $10,14 \mathrm{a}$ & \\
\hline MD & & & $28,08 \mathrm{a}$ & $54,98 \mathrm{a}$ & $6,24 c$ & & \\
\hline ME & & & $16,57 b$ & $24,96 \mathrm{c}$ & $11,70 \mathrm{abc}$ & & \\
\hline d.m.s. ${ }^{(2)}$ & & & 9,1812 & 14,0942 & 10,4196 & 2,9859 & 6,2765 \\
\hline$s^{(2)}$ & & & 4,8534 & 7,4505 & 5,5058 & 1,7710 & 4,3051 \\
\hline $\mathrm{F}^{(2)}$ & & & $5,03 * *$ & $12,79 * *$ & $4,85 * *$ & $2,02 \mathrm{~ns}$ & $0,74 \mathrm{~ns}$ \\
\hline c.v. ${ }^{(2)}$ & & & 24,34 & 20,07 & 44,98 & 16,41 & 26,60 \\
\hline \multicolumn{8}{|c|}{$9 \pm 1^{\circ} \mathrm{C}$ com $85-90 \%$ UR } \\
\hline MA & 97,49 & 24,86 & $14,23 \mathrm{a}$ & $29,41 b$ & $23,40 \mathrm{ab}$ & $12,48 b$ & $12,87 \mathrm{a}$ \\
\hline MB & & & $18,33 \mathrm{a}$ & $27,69 b$ & $27,30 \mathrm{a}$ & $11,70 \mathrm{~b}$ & $14,04 \mathrm{a}$ \\
\hline $\mathrm{MC}$ & & & $17,35 \mathrm{a}$ & $28,45 b$ & $12,67 \mathrm{c}$ & $17,16 \mathrm{a}$ & \\
\hline MD & & & $16,06 \mathrm{a}$ & $29,64 b$ & $16,38 b c$ & $13,84 \mathrm{ab}$ & \\
\hline $\mathrm{ME}$ & & & $13,84 \mathrm{a}$ & $51,86 \mathrm{a}$ & $23,01 \mathrm{ab}$ & & \\
\hline d.m.s. ${ }^{(2)}$ & & & 6,7358 & 16,8712 & 8,1241 & 4,3430 & 1,4381 \\
\hline$s^{(2)}$ & & & 3,5607 & 8,9185 & 4,2946 & 2,3978 & 3,0442 \\
\hline $\mathrm{F}^{(2)}$ & & & $2,13 \mathrm{~ns}$ & $6,73 * *$ & $9,43^{* *}$ & $5,06^{*}$ & $0,37 \mathrm{~ns}$ \\
\hline c.v. ${ }^{(2)}$ & & & 23,17 & 26,69 & 20,90 & 17,38 & 22,63 \\
\hline
\end{tabular}

A vida útil encontrada neste estudo é coerente ao encontrado por Prado et al. (2000) em abacaxi pérola minimamente processado e armazenado a $8^{\circ} \mathrm{C}$, que foi de seis dias.

\section{CONCLUSÃO}

Através dos resultados obtidos pode-se concluir que o mamão minimamente processado e tratado com água bi-destilada e solução de hipoclorito de sódio a $2 \%$ tiveram vida útil de seis dias, independente da temperatura de armazenamento; a temperatura de $9 \pm 1^{\circ} \mathrm{C}$ foi a que proporcionou as maiores perdas de massa fresca; a taxa respiratória variou durante todo o período de armazenamento; após o corte, os valores de acidez total titulável, sólidos solúveis totais e carboidratos solúveis sofreram interferência dos tratamentos e oscilaram durante todo o período de armazenamento; 
nos produtos armazenados à $5 \pm 1^{\circ} \mathrm{C}$ o uso de solução de hipoclorito de sódio e nos armazenados à $9 \pm 1^{\circ} \mathrm{C}$ o uso de água destilada sobressaiu na retenção dos teores de vitamina $\mathrm{C}$ ao final do período de armazenamento; a textura dos produtos minimamente processados, independente do tratamento e da temperatura de armazenamento, diminuiu; a aparência externa do mamão minimamente processado e tratado com água bi-destilada e solução de hipoclorito de sódio a $2 \%$ apresentaram notas dentro do limite de aceitabilidade ao final do período de armazenamento, independente da temperatura de armazenamento.

\section{AGRADECIMENTOS}

Os autores agradecem a FAPESP - Fundação de Amparo à Pesquisa do Estado de São Paulo pela concessão do auxílio financeiro para a realização deste trabalho.

\section{REFERÊNCIAS}

ALVES, R. E. Frutas do Brasil: melão - pós-colheita. Brasília: EMBRAPA Agroindústria Tropical, 2000. 44p.

AOAC - ASSOCIATION OF OFFICIAL ANALYSTICAL CHEMISTS. Official methods of analysis. Cunniff, 16 ed. 3 rd, v.2, cap. 37. 1997.

BANZATTO, D. A.; KRONKA, S. N. de. Experimentação agrícola. 3.ed. Jaboticabal: FUNEP, 1995, 247p.

BENEDETTI, B. C.; GOLINELLI, C. C.; SARANTÓPOULOS, C. I. G. L. Avaliação de pimentão minimamente processado em rodelas e tiras, armazenado mas temperaturas de 5 e $10^{\circ}$ C. In: ENCONTRO BRASILEIRO DE CIÊNCIA E TECNOLOGIA DE ALIMENTOS, 18, Porto Alegre, 2002. Anais... Porto alegre: SBCTA, 2002. p. 12411245 .

BOLIN, H. R.; HUXSOLL, C. C. Storage stability of minimally processed fruit. Journal of Food Processing and Preservation, v. 13, p. 281-292, 1989.

BOLIN, H. R.; HUXSOL, C. C. Effect of preparation procedures and storage parameters on quality retention of salada-cut lettuce. Journal Food Science, Chicago, v. 56, p. $60-62,1991$.

BOTELHO, R. V. Efeito do tratamento pós-colheita com cálcio na ocorrência de antracnose (Colletotrichum gloeosporioedes Penz) e no amadurecimento de goiabas (Psidium guajava L.) 'Branca de Kumagai'. 1996. 122 f. Dissertação (Mestrado em Horticultura) - Faculdade de Ciências Agronômicas. Universidade Estadual Paulista 'Júlio de Mesquita Filho'. Botucatu. 
BRASIL. Portaria SVS/MS nº 326, de 30 de julho de 1997. Regulamento Técnico sobre as Condições Higiênico-Sanitárias e de Boas Práticas de Fabricação para Estabelecimentos Produtores/Industrializadores de Alimentos. Diário Oficial da União, Brasília, DF, 01 ago. 1997. Seção 1.

BRECHT, J. K. Physiology of lighthly processed fruits and vegetables. HortScience, Alexandria, v. 30, n. 1, p. 18-22, 1995.

BRUNINI, M. A. Influência de formato de corte e ácido ascórbico em melão minimamente processado. Revista Nucleus, Ituverava, v.1, n.1, p. 39-46, 2004.

BURNS, J. K. Lightly processed fruits and vegetables: introduction. HortScience, Alexandria, v.30, n. 1, p. 14-15, 1995.

CANTWELL, M. Fresh-cup products: perisables handling. Newsletter, Davis, n.8, p.23, 1995.

CARLIN, F. et al. Modified atmosphere packaging of fres "ready-to-use" greated carrots in polymeric films. Journal of Food Science, Chicago, v.55, n.4, p. 1033-1038, 1990.

CHEFT, J. C.; CHEFT, H. Introduction a al bioquímica de los alimentos. Zagaroza: Acribia, 1989. v 2.

CHITARRA, M. I. F.; CHITARRA, A. B. Pós-colheita de frutos e hortaliças: fisiologia e manuseio. 2. ed. rev. e ampl. Lavras: UFLA, 2005.

CHITARRA, M. I. F. Processamento mínimo de frutas e hortaliças. Tecnologia e Treinamento Agropecuário, v.2, n.9, p.7, 1999.

CHITARRA, M.I.F. Processamento de frutas e hortaliças. Viçosa: Centro de Produções Técnicas, 1998. 88p.

DUBOIS, M. et al. Colorimetric method for determination of sugar and related substances. Analytical Chemistry, Washington, v.28, n.3, p.350-6, 1956.

DURIGAN, J. F. O processamento mínimo de frutas. In: CONGRESSO BRASILEIRO DE FRUTICULTURA, 16. Fortaleza-CE, Palestras..., Fortaleza: SBF, 2000. p. 1-12.

HUNT, J. R. Ascorbic acid: effect on ongoing iron absortion and status in iron depled young women. American Journal of Clinical Nutrition, v. 51, p. 649-655, 1990.

INSTITUTO ADOLFO LUTZ. Normas analíticas: método químico e físico para análise de alimentos. 2 ed. São Paulo: IAL, 1985, 371p. (v.1)

JERONIMO, E. M.; KANESIRO, M. A. B. Efeito da associação de armazenamento sob refrigeração e atmosfera modificada na qualidade de mangas 'Palmer'. Revista Brasilileira de Fruticultura, Jaboticabal, v.22, n.2, p.237-243, 2000. 
KADER, A. A. Postharvest Technology of Horticultural Crops. 2. ed. Oakland: University of California, Division of Agriculture and Natural Resources, 1992. p. 277281. (Publication 3311).

LAMIKANRA, O.; CHEN, J. C.; BANKS, D. et al. Biochemical and microbial changes during the storage of minimally processes cantaloupe. Journal of Agricultural and Food Chemistry, v. 48, p. 5955-5961, 2000.

LIMA, L. C. O. Processamento Mínimo de Kiwi e Mamão. In: ENCONTRO NACIONAL SOBRE PROCESSAMENTO MÍNIMO DE FRUTAS E HORTALIÇAS. Resumo... Viçosa: UFL, 2000. p. 95- 109.

O'CONNOR-SHAW, R. E.; ROBERTS, R.; FORD, A. L. et al. Shelf life minimally processed honeydew, kiwi fruit, papaya, pineapple and cantaloupe. Journal of Food Science, v. 59, p. 1202-1206, 1994.

OLIVEIRA, J. E. D.; MARCHINI, S. Ciências nutricionais. São Paulo: Savier, 1998.

PRADO, M. E. T.; VILAS BOAS, E. V. de B.; SANTOS, J. C. B. et al. Influência do hipoclorito de sódio sobre a qualidade de abacaxis minimamente processados. In: ENCONTRO NACIONAL SOBRE PROCESSAMENTO MÍNIMO DE FRUTAS E HORTALIÇAS, 2. Viçosa, 2000._Resumos... Viçosa: UFV, 2000. p.5.

ROSEN, J. C.; KADER, A. A. Postharvest technology and quality maintenance of sliced pear an strawberry fruits. Journal of Food Science, Chicago, v.54, p. 656-659, 1989.

SGARBIERI, V. C. Alimentação e nutrição. Campinas: UNICAMP, 1987. 387p.

SILVA Jr., E. A. da Manual de controle higiênico sanitário de alimentos, 4 ed. São Paulo: Varela, 2001. 432p.

TATSUMI, Y.; WATADA, A. E.; WERGIN, W.P. Scanning electron microscopy of carrot stick surface to determine cause of white translucent appearance. Journal of Food Science, v.56, p. 1357-1362, 1991.

VITTI, M. C. D. et al. Temperatura de armazenamento de tangores "Murcote" minimamente processados. Revista Brasileira de Fruticultura, v.25, n.3, p. 535-536, 2003.

WATADA, A. E.; KO, N. P.; MINOTT, D. A. Factors affecting quality of fresh-cut horticultural products. Postharvest Biology and Technology, Amsterdam, v.9, n. 2, p115-125, 1996. 